This document is the accepted manuscript version of the following article:

J. Li, S. Lampart, J. S. Siegel, K.-H. Ernst, C. Wäckerlin

Graphene grown from flat and bowl shaped polycyclic aromatic hydrocarbons on $\mathrm{Cu}(111)$

ChemPhysChem, 2019, 21, 2354-2359, https://dx.doi.org/10.1002/cphc.201900291

\title{
Graphene grown from flat and bowl shaped polycyclic aromatic hydrocarbons on $\mathrm{Cu}(111)$
}

\author{
Jingyi Li, ${ }^{[a]}$ Samuel Lampart, ${ }^{[b]}$ Jay S. Siegel ${ }^{[c]}$ Karl-Heinz Ernst, ${ }^{[a, b, d]}$ Christian Wäckerlin* ${ }^{\star a, d]}$
}

\begin{abstract}
The growth of carbon layers, defective graphene and graphene by deposition of polycyclic aromatic hydrocarbons (PAHs) on $\mathrm{Cu}(111)$ is studied by scanning tunneling microscopy and X-ray photoelectron spectroscopy. Two different PAHs are used as starting materials: the buckybowl pentaindenocorannulene (PIC) which contains pentagonal rings and planar coronene (CR). For both precursors, with increasing sample temperature during deposition, porous carbon aggregates $\left(350^{\circ} \mathrm{C}\right)$, dense carbon layers $(400-$ $\left.450^{\circ} \mathrm{C}\right)$, disordered defective graphene $\left(500^{\circ} \mathrm{C}-550^{\circ} \mathrm{C}\right)$ and extended graphene $\left(\geq 600^{\circ} \mathrm{C}\right)$ are obtained. No significant differences for defective graphene grown from PIC and CR are observed. C 1s $\mathrm{X}$-ray photoelectron spectra of PIC and CR derived samples grown at $350-550^{\circ} \mathrm{C}$ exhibit a characteristic $\mathrm{C}-\mathrm{Cu}$ low binding energy component. Preparation at $\geq 600^{\circ} \mathrm{C}$ eliminates this $\mathrm{C}$-Cu species and only $\mathrm{C}-\mathrm{C}$ bonded carbon remains.
\end{abstract}

\section{Introduction}

Structural defects in graphene ${ }^{[1]}$ are of high interest for metalfree catalysis, ${ }^{[2]}$ sensing and separation of small gaseous molecules ${ }^{[3,4]}$ band gap tuning, ${ }^{[5,6]}$ spintronics ${ }^{[7]}$ or batteries. ${ }^{[8,9]}$ In addition, there is profound theoretical interest in localized defects $^{[10-13]}$ and grain boundaries ${ }^{[14,15]}$ in graphene. Defects can be prepared from pristine graphene by electron beam irradiation, ${ }^{[6,16,17]}$ ion bombardment ${ }^{[7,18-21]}$ plasma etching ${ }^{[4]}$ or simply growth at moderate temperatures. ${ }^{[22,23]}$

On metal surfaces with low bulk solubility of carbon (e.g. Cu), graphene is grown with carbon stemming from simple gaseous hydrocarbons, ${ }^{[24-28]}$ solid carbon sources, ${ }^{[29]}$ or polycyclic aromatic hydrocarbons (PAHs).$^{[30,31]}$ In contrast to defect-free graphene, which is generally obtained at high temperatures, ${ }^{[24,32]}$ only few studies focus on the growth of graphene and defective graphene at moderate temperatures. ${ }^{[3,34]}$ For graphene grown from methane on $\mathrm{Cu}(111)$ at $800^{\circ} \mathrm{C}$, scanning tunneling microscopy (STM) reveals the formation of carbon clusters and periodically defective graphene. ${ }^{[35]}$ Growth at higher temperatures leads to defect-free extended graphene domains.

A recent report showed that, due to relative differences in the stability of dehydrogenated aggregates formed by different precursors, graphene is formed on Cu foils by annealing of paraand meta-terphenyl but not by ortho-terpyhenyl. ${ }^{[36]}$ Furthermore,

[a] Dr. J. Li, Prof. Dr. K.-H. Ernst, Dr. C. Wäckerlin

Swiss Federal Laboratories for Materials Science and Technology Überlandstr. 129, Dübendorf, Switzerland

E-mail: christian.waeckerlin@empa.ch

[b] Dr. S. Lampart, Prof. Dr. K.-H. Ernst

Department of Chemistry

University of Zurich

Winterthurerstrasse 190, 8057 Zurich, Switzerland

[c] Prof. Dr. Jay S. Siegel

School of Pharmaceutical Science and Technology Tianjin University

92 Weijin Road, Nankai District, Tianjin-3000072, China

[d] Dr. C. Wäckerlin, Prof. Dr. K.-H. Ernst

Institute of Physics of the Czech Academy of Sciences

Cukrovarnická 10, 16200 Praha 6, Czech Republic the choice of PAH used as precursor, either coronene (CR), pentacene or rubrene, is reported to affect the quality of graphene sheets grown on polycrystalline $\mathrm{Cu}$ at $1000^{\circ} \mathrm{C} .^{[31]}$ More defects in graphene prepared from pentacene and rubrene compared to graphene prepared from CR were found using Raman spectroscopy. In contrast to the predominant view that graphene growth on $\mathrm{Cu}$ proceeds via dissociation of the precursor, ${ }^{[37]}$ the above cited results suggest that the structure of the molecular precursor might play a role in graphene growth. Also quantum molecular dynamics simulations starting from $\mathrm{C}_{2}$ vs. CR precursors on $\mathrm{Ni}(111)$ find differences in intermediate graphene growth steps. ${ }^{[38]}$ To this end, this study compares the growth stages of defective graphene and graphene obtained with two different PAHs as precursors. In this work, defective graphene refers to carbon layers which contain nanometer sized graphene domains but also a high amount of structural defects. If parts of the structure of the precursor could be integrated into graphene, the synthesis of theoretically predicted twodimensional carbon allotropes such as pentagraphene ${ }^{[39,40]}$ or Haeckelites ${ }^{[41]}$ may be possible.

Here, the transformation of two different molecular precursors (Scheme 1), pentaindenocorannulene ${ }^{[42,43]}\left(\mathrm{PIC}, \mathrm{C}_{50} \mathrm{H}_{20}\right)$ and $\mathrm{CR}$ $\left(\mathrm{C}_{24} \mathrm{H}_{12}\right)$ on $\mathrm{Cu}(111)$ into defective graphene and graphene is presented. Unlike $\mathrm{CR}$, which consists of seven hexagons and can be considered (after dehydrogenation) as a subunit of graphene, PIC is a geodesic polyarene which also has 6 pentagons in its carbon backbone. The samples are prepared in ultra-high vacuum by sublimation of the precursors onto the substrate surface kept at specific temperatures and analyzed insitu using X-ray photoelectron spectroscopy (XPS) and STM.

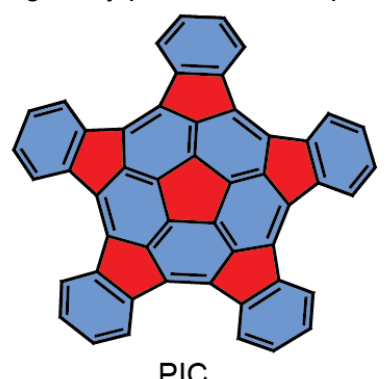

PIC

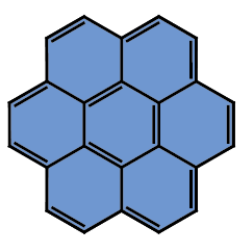

$\mathrm{CR}$
Scheme 1. Structures of precursors for graphene growth: pentaindenocorannulene (PIC) and coronene (CR). Pentagonal rings are highlighted in red, hexagonal rings in blue. PIC is dome-shaped and CR is planar.

\section{Results and Discussion}

Figure 1 and 2 show STM images of different length scale of samples produced by sublimation of PIC and $\mathrm{CR}$ on $\mathrm{Cu}(111)$ kept at different temperatures. Deposition of PIC onto the surface kept at $350^{\circ} \mathrm{C}$ (Figure $1 \mathrm{a}$ and 2a) leads to interconnected, fractal-like porous $2 \mathrm{D}$ structures growing predominantly from step edges. Internally, the aggregates consist of PIC-sized merged lobes. For pentacene annealed on 
$\mathrm{Cu}(111),{ }^{[44]}$ similar covalent networks consisting of elongated, pentacene-like lobes were reported. Thus at this temperature the structure of the precursor is still partly preserved, although partial $\mathrm{C}-\mathrm{C}$ has probably also already occured. Preparation with PIC deposited at $400^{\circ} \mathrm{C}$ and $450^{\circ} \mathrm{C}$ (Figure $1 \mathrm{~b}, \mathrm{C}$ ) leads to dense, corrugated carbon layers. Due to the high corrugation, no highresolution images were obtained on these samples. Growth at $550^{\circ} \mathrm{C}$ (Figure $1 \mathrm{~d}$ and $2 \mathrm{~b}$ ) leads to layers consisting of dark trenches pinned to the $\mathrm{Cu}$ substrate and flat areas, which correspond to small graphene domains. Growth at $600^{\circ} \mathrm{C}$ (Figure 1e) results in graphene domains with a bigger average size and fewer bright protrusions. The long ridges corresponding to domain boundaries and localized defects seen in the highresolution images (Figure 2c,d) are discussed later. Preparation at $650^{\circ} \mathrm{C}$ and $700^{\circ} \mathrm{C}$ (Figure 1f, Figure S1) leads to extended graphene domains.
With $\mathrm{CR}$ as precursor, growth at $350^{\circ} \mathrm{C}$ (Figure $1 \mathrm{~g}$ and $2 \mathrm{e}$ ) leads to porous aggregates growing from the step edges, similar to the case of PIC. Also here, the size and shape of the lobes is consistent with that of CR. STM images obtained after growth at $450^{\circ} \mathrm{C}$ (Figure $1 \mathrm{~h}$ and $2 \mathrm{f}$ ) show the further transformation of molecules into a dense carbon layer. As in case of PIC, the porous layer has disappeared and a corrugated surface along step edges is observed. Growth at $600^{\circ} \mathrm{C}$ (Figure $1 \mathrm{i}$ and $2 \mathrm{~g}$ ) results in extended graphene flakes, like in case of PIC.

On all samples, vague features or streaks are imaged. This is ascribed to mobile molecules and also is the reason why the bare substrate appears with a similar height as the PIC and CR derived carbon aggregates prepared at $350^{\circ} \mathrm{C}$ (Figure 2h). In samples prepared at higher temperatures, less streaks are observed, presumably due to either desorption of this species or its conversion to graphene.
PIC
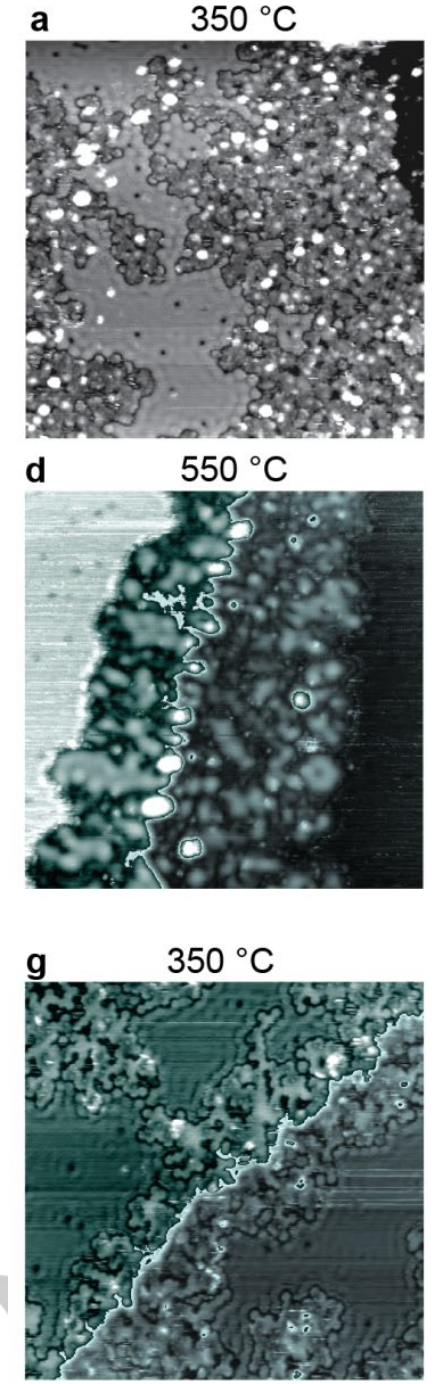

$400^{\circ} \mathrm{C}$

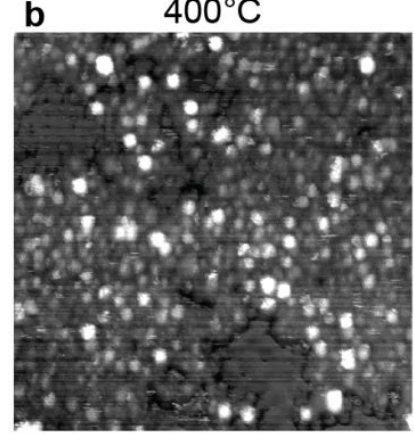

e $\quad 600^{\circ} \mathrm{C}$

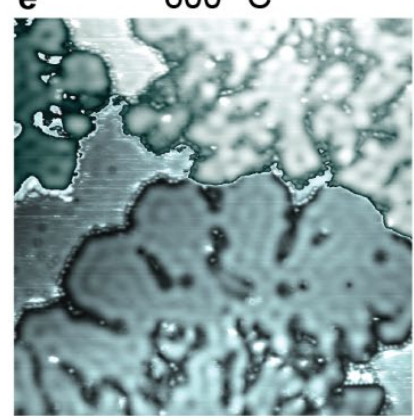

CR

h

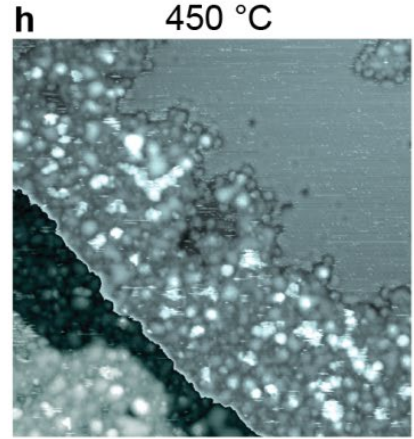

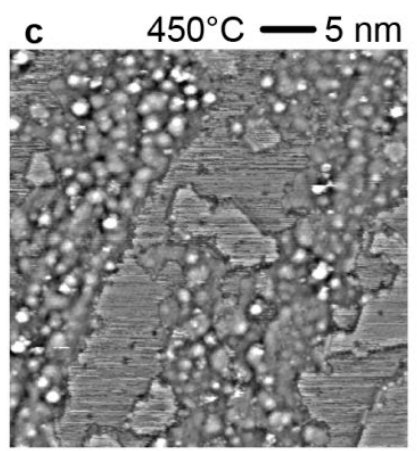

f $\quad 6500^{\circ} \mathrm{C}$

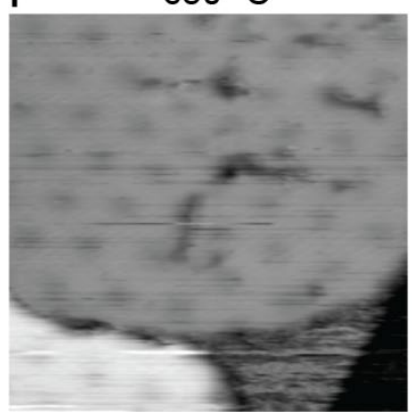

i $\quad 600^{\circ} \mathrm{C}$

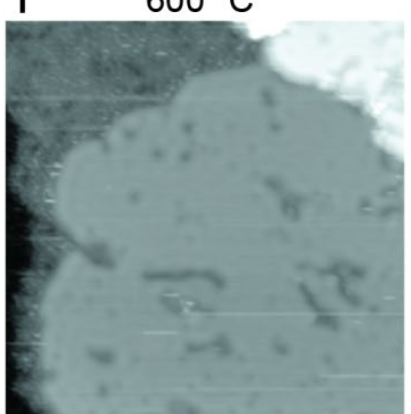

Figure 1. STM images of carbon layers grown by deposition of PIC (a-f) and CR ( $g$-i) at different sample temperatures. (a,g) Dendritic aggregates observed after growth with $\mathrm{PIC}$ and $\mathrm{CR}$ at $350^{\circ} \mathrm{C}$. (b-c, h) Deposition of $\mathrm{PIC}$ and $\mathrm{CR}$ at temperatures ranging from $400-450^{\circ} \mathrm{C}$ leads to dense layers with progressively larger graphene domains and fewer topographically high features. (d-f, i) Deposition of PIC and CR at $550-650^{\circ} \mathrm{C}$ ) leads to graphene and defective graphene layers with progressively fewer dark trenches. Imaging parameters: a) $330 \mathrm{pA}, 22 \mathrm{mV}$; b) $330 \mathrm{pA}, 24 \mathrm{mV}$; c) $220 \mathrm{pA}, 32 \mathrm{mV}$; d) $330 \mathrm{pA}, 24 \mathrm{mV}$; e) $110 \mathrm{pA}, 23 \mathrm{mV}$; f) 490 pA, $22 \mathrm{mV}$; g) 210 pA, $29 \mathrm{mV}$, h) 410 pA, $23 \mathrm{mV}$; i) 530 pA, $29 \mathrm{mV}$. For visibility, in images (d,e,g,h) the contrast is folded at step edges. 

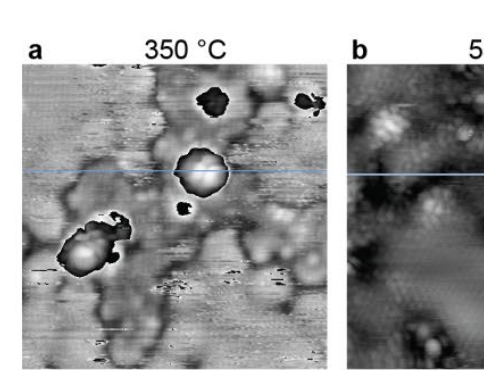

$500^{\circ} \mathrm{C}$

PIC

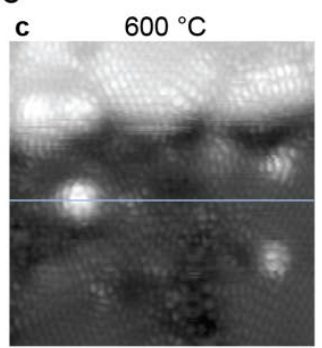

d $650^{\circ} \mathrm{C}$
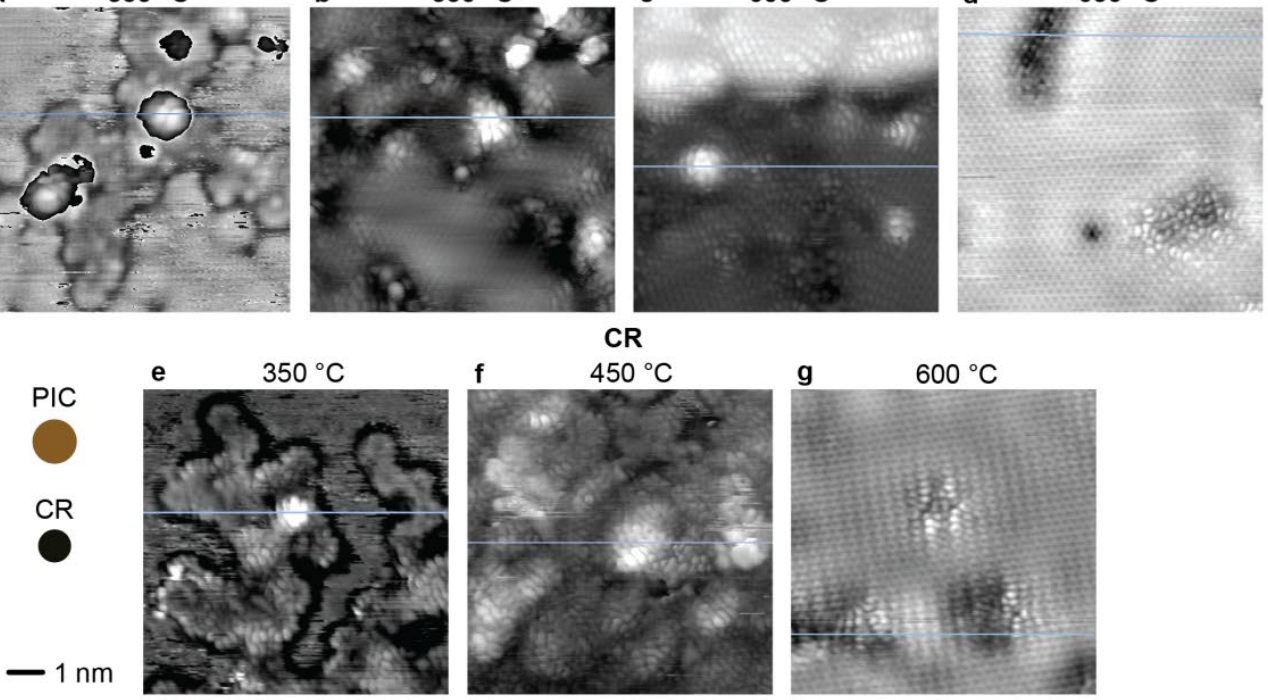

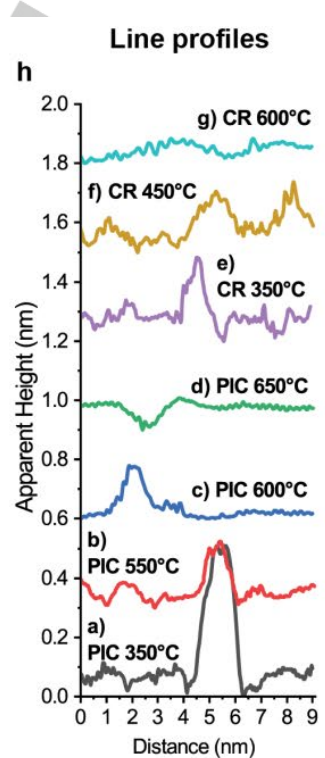

Figure 2. Small scale STM images of carbon layers grown by deposition of PIC (a-d) and CR (e-g) at different sample temperatures. The brown and black circles represent the size of the PIC and CR precursors, respectively. (h) Line profiles taken at the scan lines indicated by light blue lines in (a-g). Imaging parameters: a) $280 \mathrm{pA}, 22.3 \mathrm{mV}$ b) $310 \mathrm{pA}, 20.1 \mathrm{mV}$; c) $270 \mathrm{pA}, 28.4 \mathrm{mV}$; d) $250 \mathrm{pA}, 23.5 \mathrm{mV}$; e) $290 \mathrm{pA}, 35.3 \mathrm{mV}$; f) $250 \mathrm{pA}, 36.3 \mathrm{mV}$; $) 490 \mathrm{pA}, 25.9 \mathrm{mV}$. In image a) the image contrast is folded for visibility of the high features.

The chemical states of carbon for the different transformation stages of PIC and CR are analyzed by C 1s XP spectra (Figure $3 a, b)$. The spectra were obtained at room temperature after deposition of the molecules on the substrate kept at the indicated temperatures. For PIC deposited on $\mathrm{Cu}(111)$ kept at $27^{\circ} \mathrm{C}$, the $\mathrm{C} 1 \mathrm{~s}$ signal presents a peak centered at $284.6 \mathrm{eV}$. Graphene grown at $650^{\circ} \mathrm{C}$ and $700^{\circ} \mathrm{C}$ has a narrower $\mathrm{C}$ is signal centered at $284.8 \mathrm{eV}$, consistent with previously reported $\mathrm{XP}$ spectra of graphene/Cu(111). ${ }^{[45]}$ Interestingly, the samples grown at intermediate temperatures $\left(350^{\circ} \mathrm{C}-550^{\circ} \mathrm{C}\right)$ exhibit an additional $C$ is signal at lower binding energy. In agreement with reported $\mathrm{C} 1 \mathrm{~s}$ binding energies for carbon binding to $\mathrm{Cu}$ or $\mathrm{Ag}$ (283.1 to $284.0 \mathrm{eV}),{ }^{[46-51]}$, the low binding energy carbon species is identified as carbon interacting with the $\mathrm{Cu}$ substrate. For simplicity, we call this low binding energy species "organometallic carbon" [51] although it most likely represents a number of different types $\mathrm{C}-\mathrm{Cu}$ species.

The $C$ 1s XP spectra of carbon layers grown from $C R$ are very similar (Figure $3 b$ ) to the ones grown from PIC. CR deposited on $\mathrm{Cu}(111)$ kept at room temperature has a $\mathrm{C} 1 \mathrm{~s}$ binding energy of $284.8 \mathrm{eV}$. The slight difference in binding energy and narrower line shape with respect to PIC is attributed to their different structure. For graphene grown from $\mathrm{CR}$ at $600^{\circ} \mathrm{C}$, the $\mathrm{C}$ 1s binding energy of $284.8 \mathrm{eV}$ is identical to the one of graphene grown from PIC. Like in case of PIC-derived carbon layers, an additional $C$ 1s signal at lower binding energies is present for carbon layers grown from $\mathrm{CR}$ at intermediate temperatures.

The C 1s spectra are deconvoluted by peak fitting with Voigt functions ( $50 \%$ Gaussian and $50 \%$ Lorentzian). The peak fits are constrained in order to reduce the number of free parameters: First, the binding energy $(284.8 \mathrm{eV})$ and FWHM $(1.3 \mathrm{eV})$ of graphenic carbon is determined from the $700^{\circ} \mathrm{C}$ sample and kept identical for the other spectra (dashed red arrow). Second, a organometallic component with identical fixed FWHM $(1.3 \mathrm{eV})$ is fitted with the $450^{\circ} \mathrm{C}$ PIC data where the low binding energy shoulder is most intense. This yields a binding energy of 284.1 $\mathrm{eV}$ for organometallic carbon which is then also kept fixed. Finally, the other PIC and CR spectra are fitted with the same two components, with the exception of $\mathrm{PIC}$ at $27^{\circ} \mathrm{C}$ and $350^{\circ} \mathrm{C}$ where the molecular $\mathrm{C}$ signal (binding energy $284.6 \mathrm{eV}$, FWHM $1.7 \mathrm{eV})$ instead of the graphenic one $(284.8 \mathrm{eV})$ is used.

The fraction of organometallic $\mathrm{C}$ obtained by this analysis is shown in Figure 3c. It should be noted however, that the magnitude of the chemical shift between graphenic and organometallic carbon $(0.7 \mathrm{eV})$ compared to the energy resolution $(1.1 \mathrm{eV})$ limits the precision of this analysis.

The significant organometallic $\mathrm{C}-\mathrm{Cu}$ fraction in $\mathrm{PIC}$ and $\mathrm{CR}$ derived samples prepared at $350^{\circ} \mathrm{C}$ in combination with the presence of fractal aggregates (Figure 1 and 2) which still resemble the structure of the precursors, indicates that at this stage the aggregation is primarily induced by (non-specific) $\mathrm{C}-\mathrm{H}$ activation via dehydrogenation, consistent with the literature. ${ }^{[52-}$ 55]

In samples prepared at $400^{\circ} \mathrm{C}$ to $550^{\circ} \mathrm{C}$, the $\mathrm{C}-\mathrm{Cu}$ fraction reaches $\sim 60 \%$. This high organometallic peak fraction exceeds the fraction of carbon atoms which can undergo $\mathrm{C}-\mathrm{H}$ activation (40\% for PIC and $50 \%$ for $\mathrm{CR}$ ) and thus indicates (unspecific) $\mathrm{C}-\mathrm{C}$ bond breaking. This is consistent with STM data (Figure 1 and 2) which shows the formation dense carbon layers and defective graphene.

Interestingly, despite the presence of defective graphene domains in samples grown at $500-550^{\circ} \mathrm{C}$, the peak fraction of organometallic carbon remains high and drops only at $600^{\circ} \mathrm{C}$ where the first extended graphene domains are observed. In 
contrast, organometallic C-metal species produced e.g. by Ullmann chemistry are converted already at around $200-300^{\circ} \mathrm{C}$ to $\mathrm{C}-\mathrm{C}$ bonds. ${ }^{[46,47,50,51,56]}$ Thus the growth dynamics at $400-$ $550^{\circ} \mathrm{C}$ presumably involves an equilibrium between $\mathrm{C}-\mathrm{C}$ and $\mathrm{C}-$ $\mathrm{Cu}$ bond formation and breaking. It is also likely that the dark trenches in between of defective graphene domains contribute to the $\mathrm{C}-\mathrm{Cu}$ signal. Howerver, it is important to note that the existence of mobile species in STM which also contribute to the C 1s XP signal, does not allow for a quantitative comparision of STM and XPS data.

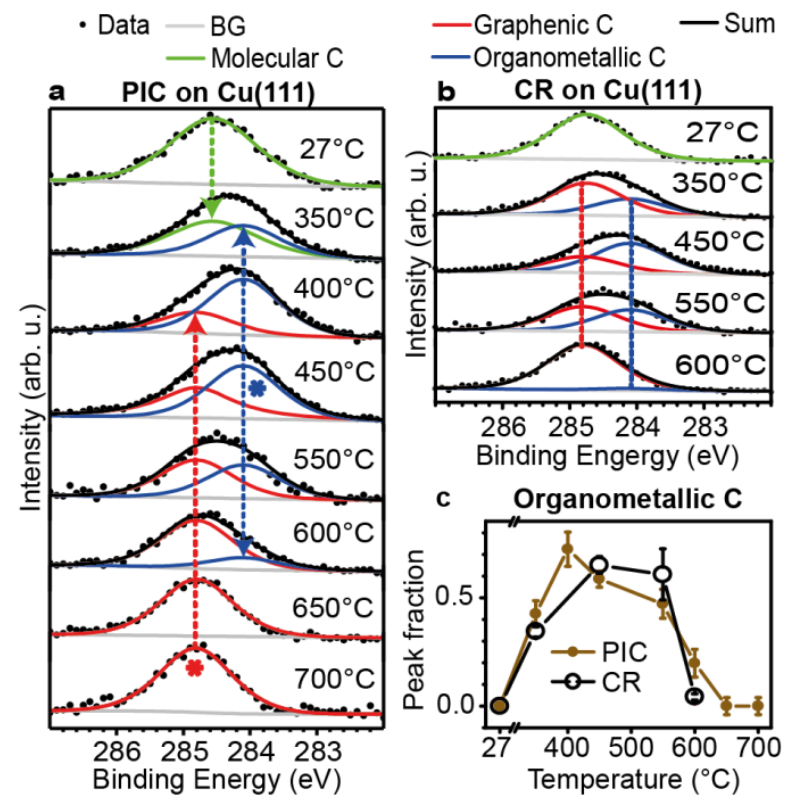

Figure 3. C 1s XP spectra of recorded after deposition of PIC (a) and CR (b) kept at the indicated temperatures. The spectra are deconvolved into graphenic, organometallic and molecular carbon components with fixed binding energies and widths (see text). The * signs and the dashed arrows and lines indicate the components which have been fitted freely and the related components with fixed binding energies and widths. The XPS intensities are normalized for visibility. (c) Peak fraction of organometallic carbon.
High resolution STM images of defective graphene domains grown from both PIC and CR at show localized defects (Figure 4). The trenches correspond to grain boundaries. ${ }^{[1]}$ The rotation of the graphene lattice by $12^{\circ}$ is indicated by blue arrows. Three different kinds of localized defects can be observed (marked with red squares). Based on the very good agreement with simulated STM images discussed in refs. [12,57], the defects shown in Figure $4 b$ and $4 c$ are most likely i) flower defects (rotational grain boundary with symmetry consisting of six pairs of hepta- and penta-rings) and ii) Stone-Wales defects ${ }^{[57]}$ (two pairs of pentagonal and heptagonal rings). The defect shown in Figure $4 \mathrm{c}$ is most likely a point defect (e.g. vacancy ${ }^{[58]}$ or an incorporated heteroatom ${ }^{[59]}$ ). Notably, localized defects also occur in graphene grown from CR (Figure 4e). Their distorted appearance is presumably related to an imperfect tip.

\section{Conclusions}

In summary, deposition of either PIC and $\mathrm{CR}$ on hot $\mathrm{Cu}(111)$ surfaces leads to carbon layers which can be qualitatively described as porous carbon aggregates $\left(350^{\circ} \mathrm{C}\right)$, dense carbon layers $\left(400^{\circ} \mathrm{C}-450^{\circ} \mathrm{C}\right)$, defective graphene consisting of nanometer sized graphene domains $\left(500^{\circ} \mathrm{C}-550^{\circ} \mathrm{C}\right)$ and extended graphene $\left(\geq 600^{\circ} \mathrm{C}\right)$. In view of the different appearance with respect to carbon aggregates grown from pentacene,${ }^{[4]}$ in the porous aggregate regime $\left(350^{\circ} \mathrm{C}\right)$ the precursors are still partly preserved. At higher temperatures, no significant differences of the carbon structures grown from PIC and CR are apparent. No haeckelites, pentagraphene or ordered defective graphene ${ }^{[35]}$ are obtained. Local defects are found both in PIC and CR derived graphene.
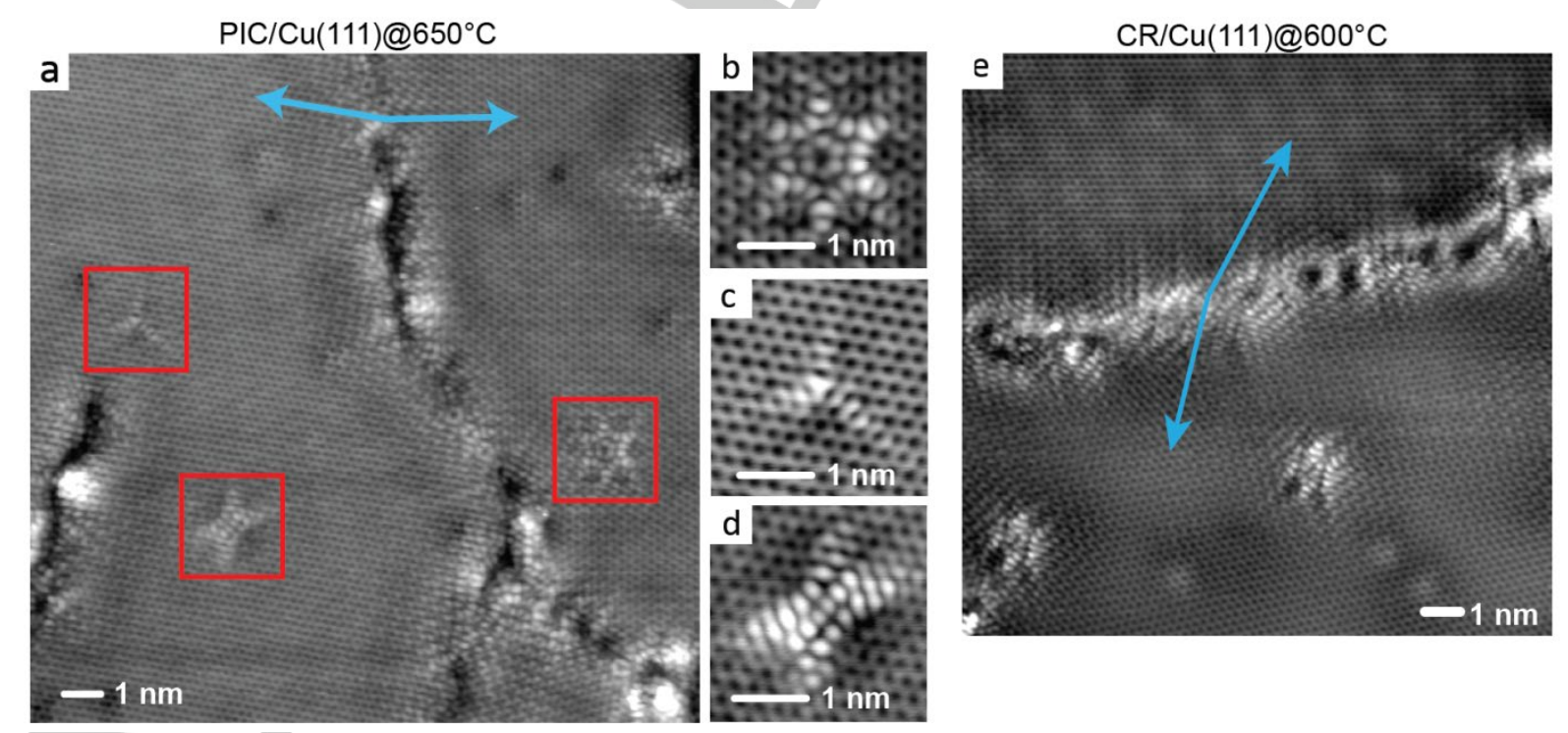

Figure 4. Graphene layers grown from PIC and CR containing localized defects. Images (a-d) were obtained after deposition of $\mathrm{PIC}$ onto $\mathrm{Cu}(111)$ kept at $650^{\circ} \mathrm{C}$ and subsequent annealing at $600^{\circ} \mathrm{C}$ for one hour without further evaporation of molecules. Blue arrows labels two rotational domains of produced graphene separated by grain boundaries. Three red boxes label the locations of three different local defects, shown in images (b-d) respectively. Image (e) is obtained after evaporation of $\mathrm{CR}$ onto $\mathrm{Cu}(111)$ kept at $600^{\circ} \mathrm{C}$ and subsequent annealing for $30 \mathrm{~min}$. Blue arrows label the lattice directions at the grain boundaries. Imaging parameters: a) $390 \mathrm{pA}, \quad 22.9 \mathrm{mV} ; \quad$ b) $1.15 \mathrm{nA}, \quad 24.4 \mathrm{mV} ; \quad$ c) $49 \mathrm{pA}, \quad 22.8 \mathrm{mV} ; \quad$ d) 62 pA, 23.5 mV; e) 240 pA, $27.5 \mathrm{mV}$ 


\section{Experimental Section}

Sample preparation: The experiments were performed in-situ in ultra-high vacuum on $\mathrm{Cu}(111)$ (MaTecK $\mathrm{GmbH})$. The base pressure was $3 \times 10^{-10}$ mbar. The substrate was cleaned by cycles of $\mathrm{Ar}^{+}$ion sputtering and annealing. PIC (University of Zürich) and CR (Sigma-Aldrich, 99\%, purified by resublimation) was sublimed from Knudsen cells onto the samples held at different temperatures. Different sublimation times (15$60 \mathrm{~min}$ ) were chosen in order to obtain carbon layers with similar coverages. Unless specified otherwise, the samples were kept at a fixed, elevated temperature during deposition for $5 \mathrm{~min}$ after stopping the deposition before allowing them to cool down to room temperature.

$X$-ray photoelectron spectroscopy: XP spectra were measured at room temperature using non-monochromatic Al $\mathrm{K}_{\alpha} \mathrm{X}$-rays in normal emission. The binding energy scale was calibrated on the clean $\mathrm{Cu}$ surface using the $\mathrm{Cu} 2 \mathrm{p}_{3 / 2}$ core level $(932.7 \mathrm{eV})$ and the Fermi level $(0.0 \mathrm{eV})$.

Scanning tunneling microscopy: STM images were acquired at room temperature in constant current mode and with a Ptlr tip. The tip was mechanically cut and then sputtered by $\mathrm{Ar}^{+}$ions in-situ. The STM images were processed using WSxM. ${ }^{[60]}$

\section{Acknowledgements}

Financial support by the University of Zürich research priority program LightChEC and by the Swiss National Foundation (R'Equip, grant No. P300P2_177755) is gratefully acknowledged.

\section{Conflict of Interest}

The authors declare no conflict of interest.

Keywords: graphene, copper surface, defective graphene, scanning tunneling microscopy, $x$-ray photoelectron spectroscopy

[1] O. V. Yazyev, Y. P. Chen, Nat. Nanotechnol. 2014, 9, 755.

[2] C. Su, K. P. Loh, Acc. Chem. Res. 2013, 46, 2275

[3] Y.-H. Zhang, Y.-B. Chen, K.-G. Zhou, C.-H. Liu, J. Zeng, H.-L. Zhang, Y. Peng, Nanotechnology 2009, 20, 185504.

[4] J. Zhao, G. He, S. Huang, L. F. Villalobos, M. Dakhchoune, H. Bassas, K. V. Agrawal, Sci. Adv. 2019, 5, eaav1851.

[5] T. Guerra, S. Azevedo, M. Machado, Eur. Phys. J. B 2016, 89, 58.

[6] J. Kotakoski, A. V. Krasheninnikov, U. Kaiser, J. C. Meyer, Phys. Rev. Lett. 2011, 106, 105505.

[7] J.-H. Chen, L. Li, W. G. Cullen, E. D. Williams, M. S. Fuhrer, Nat. Phys. 2011, 7, 535.

[8] D. Er, E. Detsi, H. Kumar, V. B. Shenoy, ACS Energy Lett. 2016, 1, 638.

[9] R. Mukherjee, A. V. Thomas, D. Datta, E. Singh, J. Li, O. Eksik, V. B. Shenoy, N. Koratkar, Nat. Commun. 2014, 5, DOI 10.1038/ncomms4710.

[10] G.-D. Lee, C. Z. Wang, E. Yoon, N.-M. Hwang, D.-Y. Kim, K. M. Ho, Phys. Rev. Lett. 2005, 95, 205501.

[11] B. W. Jeong, J. Ihm, G.-D. Lee, Phys. Rev. B 2008, 78, 165403.

[12] E. Cockayne, G. M. Rutter, N. P. Guisinger, J. N. Crain, P. N. First, J. A. Stroscio, Phys. Rev. B 2011, 83, 195425.

[13] E. Cockayne, Phys. Rev. B 2012, 85, 125409.

[14] O. V. Yazyev, S. G. Louie, Phys. Rev. B 2010, 81, 195420.

[15] A. Luican-Mayer, J. E. Barrios-Vargas, J. T. Falkenberg, G. Autès, A. W. Cummings, David Soriano, G. Li, M. Brandbyge, O. V. Yazyev, S. Roche, E. Y. Andrei, 2D Mater. 2016, 3, 031005.
[16] T. Björkman, S. Kurasch, O. Lehtinen, J. Kotakoski, O. V. Yazyev A. Srivastava, V. Skakalova, J. H. Smet, U. Kaiser, A. V. Krasheninnikov, Sci. Rep. 2013, 3, 3482.

[17] A. Hashimoto, K. Suenaga, A. Gloter, K. Urita, S. lijima, Nature 2004, 430, 870

[18] G. Compagnini, F. Giannazzo, S. Sonde, V. Raineri, E. Rimini, Carbon 2009, 47, 3201.

[19] G. López-Polín, C. Gómez-Navarro, V. Parente, F. Guinea, M. I. Katsnelson, F. Pérez-Murano, J. Gómez-Herrero, Nat. Phys. 2015 $11,26$.

[20] M. M. Ugeda, D. Fernández-Torre, I. Brihuega, P. Pou, A. J. Martínez-Galera, R. Pérez, J. M. Gómez-Rodríguez, Phys. Rev. Lett. 2011, 107, 116803.

[21] S. Standop, O. Lehtinen, C. Herbig, G. Lewes-Malandrakis, F. Craes, J. Kotakoski, T. Michely, A. V. Krasheninnikov, C. Busse Nano Lett. 2013, 13, 1948.

[22] J. Coraux, A. T. N'Diaye, C. Busse, T. Michely, Nano Lett. 2008, 8, 565.

[23] G. M. Rutter, J. N. Crain, N. P. Guisinger, T. Li, P. N. First, J. A. Stroscio, Science 2007, 317, 219.

[24] X. Li, W. Cai, J. An, S. Kim, J. Nah, D. Yang, R. Piner, A Velamakanni, I. Jung, E. Tutuc, S. K. Banerjee, L. Colombo, R. S. Ruoff, Science 2009, 324, 1312.

[25] X. Li, C. W. Magnuson, A. Venugopal, R. M. Tromp, J. B. Hannon, E. M. Vogel, L. Colombo, R. S. Ruoff, J. Am. Chem. Soc. 2011, 133, 2816.

[26] J. Coraux, A. T. N'Diaye, C. Busse, T. Michely, Nano Lett. 2008, 8 , 565.

[27] J. Coraux, A. T. N'Diaye, M. Engler, C. Busse, D. Wall, N Buckanie, F.-J. M. zu Heringdorf, R. van Gastel, B. Poelsema, T. Michely, New J. Phys. 2009, 11, 023006

[28] L. Zhao, K. T. Rim, H. Zhou, R. He, T. F. Heinz, A. Pinczuk, G. W. Flynn, A. N. Pasupathy, Solid State Commun. 2011, 151, 509.

[29] B. Kiraly, E. V. Iski, A. J. Mannix, B. L. Fisher, M. C. Hersam, N. P. Guisinger, Nat. Commun. 2013, 4, 2804.

[30] L. E. Dinca, F. De Marchi, J. M. MacLeod, J. Lipton-Duffin, R. Gatti, D. Ma, D. F. Perepichka, F. Rosei, Nanoscale 2015, 7, 3263.

[31] X. Wan, K. Chen, D. Liu, J. Chen, Q. Miao, J. Xu, Chem. Mater 2012, 24, 3906

[32] H. Kim, C. Mattevi, M. R. Calvo, J. C. Oberg, L. Artiglia, S. Agnoli, C. F. Hirjibehedin, M. Chhowalla, E. Saiz, ACS Nano 2012, 6, 3614.

[33] Z. Li, P. Wu, C. Wang, X. Fan, W. Zhang, X. Zhai, C. Zeng, Z. Li, J. Yang, J. Hou, ACS Nano 2011, 5, 3385.

[34] B. Zhang, W. H. Lee, R. Piner, I. Kholmanov, Y. Wu, H. Li, H. Ji, R. S. Ruoff, ACS Nano 2012, 6, 2471.

[35] T. Niu, M. Zhou, J. Zhang, Y. Feng, W. Chen, J. Am. Chem. Soc. 2013, 135, 8409 .

[36] K. Gharagozloo-Hubmann, N. S. Müller, M. Giersig, C. Lotze, K. J. Franke, S. Reich, J. Phys. Chem. C 2016, 120, 9821.

[37] K. Celebi, M. T. Cole, J. W. Choi, F. Wyczisk, P. Legagneux, N Rupesinghe, J. Robertson, K. B. K. Teo, H. G. Park, Nano Lett 2013, 13, 967.

[38] Y. Wang, A. J. Page, Y. Nishimoto, H.-J. Qian, K. Morokuma, S Irle, J. Am. Chem. Soc. 2011, 133, 18837.

[39] S. Zhang, J. Zhou, Q. Wang, X. Chen, Y. Kawazoe, P. Jena, Proc Natl. Acad. Sci. 2015, 112, 2372

[40] C. P. Ewels, X. Rocquefelte, H. W. Kroto, M. J. Rayson, P. R. Briddon, M. I. Heggie, Proc. Natl. Acad. Sci. 2015, 201520402.

[41] H. Terrones, M. Terrones, E. Hernández, N. Grobert, J.-C. Charlier, P. M. Ajayan, Phys. Rev. Lett. 2000, 84, 1716.

[42] E. A. Jackson, B. D. Steinberg, M. Bancu, A. Wakamiya, L. T. Scott, J. Am. Chem. Soc. 2007, 129, 484.

[43] S. Lampart, L. M. Roch, A. K. Dutta, Y. Wang, R. Warshamanage, A. D. Finke, A. Linden, K. K. Baldridge, J. S. Siegel, Angew. Chem. Int. Ed. 2016, 55, 14648

[44] L. E. Dinca, F. De Marchi, J. M. MacLeod, J. Lipton-Duffin, R. Gatti, D. Ma, D. F. Perepichka, F. Rosei, Nanoscale 2015, 7, 3263. 
[45] D. G. Matei, N.-E. Weber, S. Kurasch, S. Wundrack, M. Woszczyna, M. Grothe, T. Weimann, F. Ahlers, R. Stosch, U. Kaiser, A. Turchanin, Adv. Mater. 2013, 25, 4146.

[46] Y.-Q. Zhang, N. Kepčija, M. Kleinschrodt, K. Diller, S. Fischer, A. C. Papageorgiou, F. Allegretti, J. Björk, S. Klyatskaya, F. Klappenberger, M. Ruben, J. V. Barth, Nat. Commun. 2012, 3 1286.

[47] K. A. Simonov, N. A. Vinogradov, A. S. Vinogradov, A. V. Generalov, E. M. Zagrebina, G. I. Svirskiy, A. A. Cafolla, T. Carpy, J. P. Cunniffe, T. Taketsugu, A. Lyalin, N. Mårtensson, A. B Preobrajenski, ACS Nano 2015, 9, 8997.

[48] A. Rieger, S. Schnidrig, B. Probst, K.-H. Ernst, C. Wäckerlin, J. Phys. Chem. C 2017, 121, 27521.

[49] A. Mairena, M. Wienke, K. Martin, N. Avarvari, A. Terfort, K.-H. Ernst, C. Wäckerlin, J. Am. Chem. Soc. 2018, 140, 7705.

[50] J. Li, K. Martin, N. Avarvari, C. Wäckerlin, K.-H. Ernst, Chem. Commun. 2018, 54, 7948.

[51] M. Lackinger, Chem. Commun. 2017, 53, 7872

[52] A. Wiengarten, K. Seufert, W. Auwärter, D. Ecija, K. Diller, F. Allegretti, F. Bischoff, S. Fischer, D. A. Duncan, A. C.
Papageorgiou, F. Klappenberger, R. G. Acres, T. H. Ngo, J. V. Barth, J. Am. Chem. Soc. 2014, 136, 9346.

[53] M. Röckert, M. Franke, Q. Tariq, S. Ditze, M. Stark, P. Uffinger, D. Wechsler, U. Singh, J. Xiao, H. Marbach, H.-P. Steinrück, O. Lytken, Chem. - Eur. J. 2014, 20, 8948.

[54] M. Röckert, M. Franke, Q. Tariq, D. Lungerich, N. Jux, M. Stark, A. Kaftan, S. Ditze, H. Marbach, M. Laurin, J. Libuda, H.-P. Steinrück, O. Lytken, J. Phys. Chem. C 2014, 118, 26729.

[55] Y. He, M. Garnica, F. Bischoff, J. Ducke, M.-L. Bocquet, M. Batzill, W. Auwärter, J. V. Barth, Nat. Chem. 2017, 9, 33.

[56] L. Dong, P. N. Liu, N. Lin, Acc. Chem. Res. 2015, 48, 2765.

[57] E. Cockayne, Phys. Rev. B 2012, 85, 125409.

[58] M. M. Ugeda, I. Brihuega, F. Guinea, J. M. Gómez-Rodríguez, Phys. Rev. Lett. 2010, 104, 096804.

[59] A. R. Botello-Méndez, S. M.-M. Dubois, A. Lherbier, J.-C. Charlier, Acc. Chem. Res. 2014, 47, 3292

[60] I. Horcas, R. Fernández, J. M. Gómez-Rodríguez, J. Colchero, J. Gómez-Herrero, A. M. Baro, Rev. Sci. Instrum. 2007, 78, 013705. 


\section{Entry for the Table of Contents}

\section{ARTICLE}

Sublimation of planar and bowlshaped precursors on a copper surface kept at elevated temperatures leads to carbon layers with varying morphology: porous aggregates, disordered and dense carbon layers, defective graphene and extended graphene.

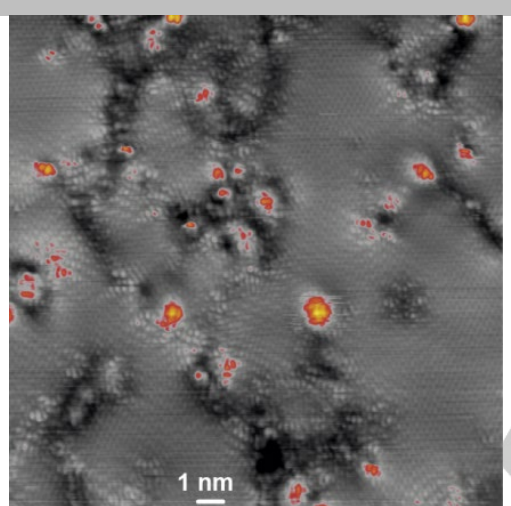

Jingyi Li, Samuel Lampart, Jay S. Siegel, Karl-Heinz Ernst, Christian Wäckerlin

Page No. - Page No.

Graphene grown from flat and bowl shaped polycyclic aromatic hydrocarbons on $\mathrm{Cu}(111)$ 